\title{
Bilateral Adrenal Leiomyoma: A Rare Tumor With Unusual Presentation
}

\author{
Amy Cheng-Mei Khor ${ }^{\mathrm{a}, \mathrm{b}}$, Naveen Rajaratnam ${ }^{\mathrm{a}}$
}

\begin{abstract}
Adrenal leiomyoma is a rare tumor. Bilateral adrenal leiomyoma is even rarer. Most of the patients with adrenal leiomyoma are asymptomatic. Hence, it was found incidentally most of the time. Some of the patients with huge tumor might complain of abdominal pain, fatigue or weigh loss. In this study, we report a middle-aged gentleman with bilateral huge adrenal leiomyoma, who presented with recurrent episodes of syncopal attack due to hypoglycemia.
\end{abstract}

Keywords: Adrenal leiomyoma; Hypoglycemia; Benign adrenal tumor

\section{Introduction}

Leiomyoma is a common benign smooth muscle tumor that can occur in any organ. Adrenal lesions are common and often discovered incidentally [1]. However, leiomyoma of adrenal gland is very rare. Bilateral adrenal leiomyoma is even rarer. Most of the patients with adrenal leiomyoma are asymptomatic. Hence, adrenal leiomyoma is always discovered during a radiological examination performed for indication other than an evaluation of adrenal disease [2]. Patients with huge adrenal leiomyoma may present with abdominal pain [3, 4]. The clinical and radiological features of a huge adrenal leiomyoma might be mistaken as a malignant tumor. In this study, we report a middle-aged gentleman with bilateral huge adrenal mass, which initially was thought to be malignant but subsequently confirmed as a leiomyoma through histopathological examination.

References for review of literature were identified through searches of PubMed and Medline for articles published to June 2020 using the terms "adrenal leiomyoma".

Manuscript submitted June 9, 2020, accepted June 16, 2020

Published online August 26, 2020

aDepartment of General Surgery, Hospital Tengku Ampuan Rahimah, Jalan Langat, 41200 Klang, Selangor, Malaysia

${ }^{b}$ Corresponding Author: Amy Cheng-Mei Khor, Department of General Surgery, Hospital Tengku Ampuan Rahimah, Jalan Langat, 41200 Klang, Selangor, Malaysia. Email: akchengmmei@gmail.com

doi: https://doi.org/10.14740/jem655

\section{Case Report}

A 38-year-old Indian man presented with recurrent episodes of syncopal attack due to hypoglycemia. Clinically he was normal built, with no neurological deficit. His blood pressure was normal, and his abdomen was soft with no palpable mass. Contrast-enhanced computed tomography (CECT) of abdomen was ordered to rule out insulinoma, and bilateral large lobulated well-defined suprarenal masses with internal coarse calcification were found (Fig. 1). The right mass was measured at $12.9 \times 11.9 \times 15.5 \mathrm{~cm}$ and left mass was measured at 10.9 $\times 11.0 \times 14.8 \mathrm{~cm}$. He was tested negative for the human immunodeficiency viruses (HIV) and Epstein-Barr virus (EBV). Biochemical investigations included electrolytes, synacthen test and urinary metanephrine were normal. Ultrasoundguided biopsy done with histopathological examination was suggestive of well-differentiated leiomyosarcoma. Bilateral adrenalectomy was done via transabdominal approach. Two multilobulated masses weighing at $1,340 \mathrm{~g}$ and $850 \mathrm{~g}$ were resected, respectively (Fig. 2). Histological examination revealed a circumscribed tumor composed of spindle cells arranged in fascicles and interlacing bundles and focal storiform pattern with extensive hyalinization. The mitotic figures are

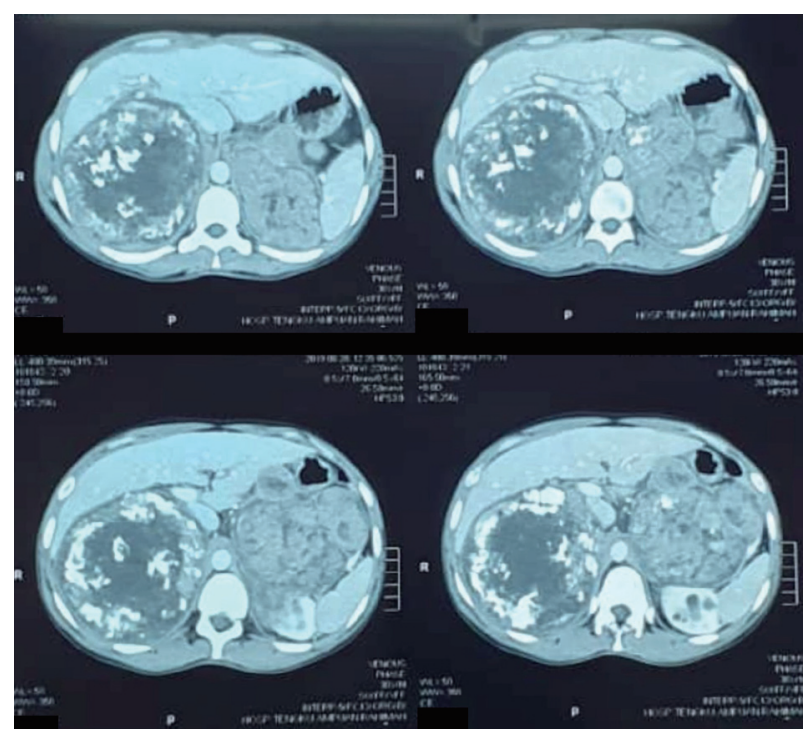

Figure 1. Contrasted CT of abdomen showing bilateral large welldefined heterogenous suprarenal mass with internal calcification. CT: computed tomography. 


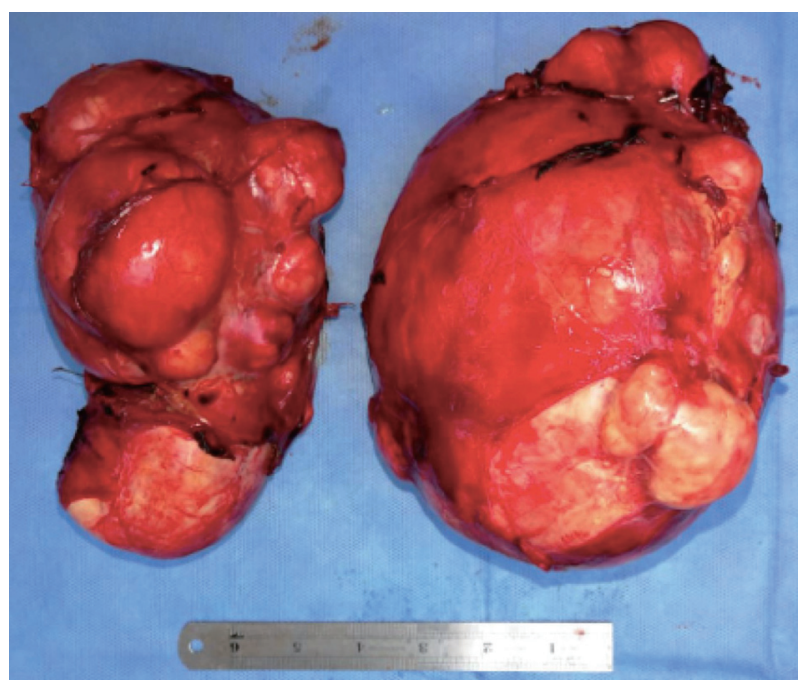

Figure 2. Gross pathology specimen showing bilateral lobulated, wellencapsulated adrenal tumor.

hardly found. Immunochemical stain for muscle-specific actin was positive. All these features are consistent with leiomyoma. The patient was recovered well postoperatively. He was maintained on low-dose hydrocortisone postoperatively and had no further episode of hypoglycemia observed.

\section{Discussion}

Leiomyoma of adrenal gland is rare. It is arising from the smooth muscle of the adrenal vein and its tributaries [4]. It is usually asymptomatic and found incidentally during CT scanning. A few cases reported symptoms of abdominal or back pain, fatigue and weight loss when tumor is large in size [3-6]. Pramod et al reported a patient with history of hepatitis B, who presented with abdominal pain associated with weight loss and fatigue and was found to have a right adrenal gland leiomyoma. The tumor was measured at $14.1 \times 11.4 \times 10.1 \mathrm{~cm}$, weighed at $600 \mathrm{~g}$, by far the largest reported adrenal leiomyoma [6].

Twenty-three cases of adrenal leiomyoma have been reported (summarized in Table 1) [3-25], and most of them are unilateral. Bilateral adrenal tumor was found predominantly in pediatric age group. Only one adult case of bilateral adrenal tumor was reported by Kumar. It was found in a 55-year-old lady with history of pulmonary tuberculosis [7]. In a few reported cases, leiomyoma of adrenal gland was associated with immunocompromised patients with acquired immunodeficiency syndrome (AIDS) [8-12]. Out of 23 reported cases, seven cases were associated with AIDS, two cases with history of pulmonary tuberculosis and one case with concurrent Hashimoto's thyroiditis. EBV has been identified in tumor cells of leiomyoma in AIDS patients [13]. It has been postulated HIV infection may promote smooth muscle tumors through direct or indirect oncogenic stimulatory effects [4]. However, more cases need to be studied.

Clinical and radiological features of adrenal leiomyoma always make it difficult to be differentiated from other malig- nant causes [5]. Hence, histopathological examination is the only confirmatory test and the only gold standard. A solid, well-circumscribed tan mass with central hyalinization will be revealed in a gross histopathological specimen of adrenal leiomyoma. Mitotic activity in adrenal leiomyoma cells is low. Bland looking spindle cells in a background of hyalinization will be seen in the histological examination of the tumor. Immunohistochemically, the tumor tissue will be stained positive for smooth muscle actin [21]. Surgical resection is the standard of care for adrenal leiomyoma. It can be done through laparoscopic or open transabdominal approach according to the center or availability of specialty.

As compared to the previous reports, our patient was not immunocompromised. His first presentation was hypoglycemia with syncopal attack. This may be due to adrenal insufficiency induced by the huge bilateral adrenal leiomyoma. It might be the largest reported bilateral adrenal leiomyoma. Even though bilateral adrenal mass is commonly caused by metastatic or infiltrative disease, adrenal leiomyoma can be considered as one of the differential diagnoses for huge nonfunctional adrenal lesion found in a generally well-built patient.

\section{Conclusions}

Adrenal leiomyoma is rare. Its clinical and radiological features can mimic malignant causes of adrenal tumor, especially in our case; the bilateral adrenal tumor with internal calcification was mistaken for malignancy. Surgical resection is always the standard of care.

\section{Acknowledgments}

We thank the patient for allowing us to share his details, and thank Dato' Seri Dr Mohamed Yusof, consultant general surgery for providing his expert opinion in managing this patient.

\section{Financial Disclosure}

None to declare.

\section{Conflict of Interest}

None to declare.

\section{Informed Consent}

Written informed consent was obtained from the patient for publication of this case report and the accompanying images.

\section{Author Contributions}

Study concept and manuscript review: Naveen Rajaratnam. 

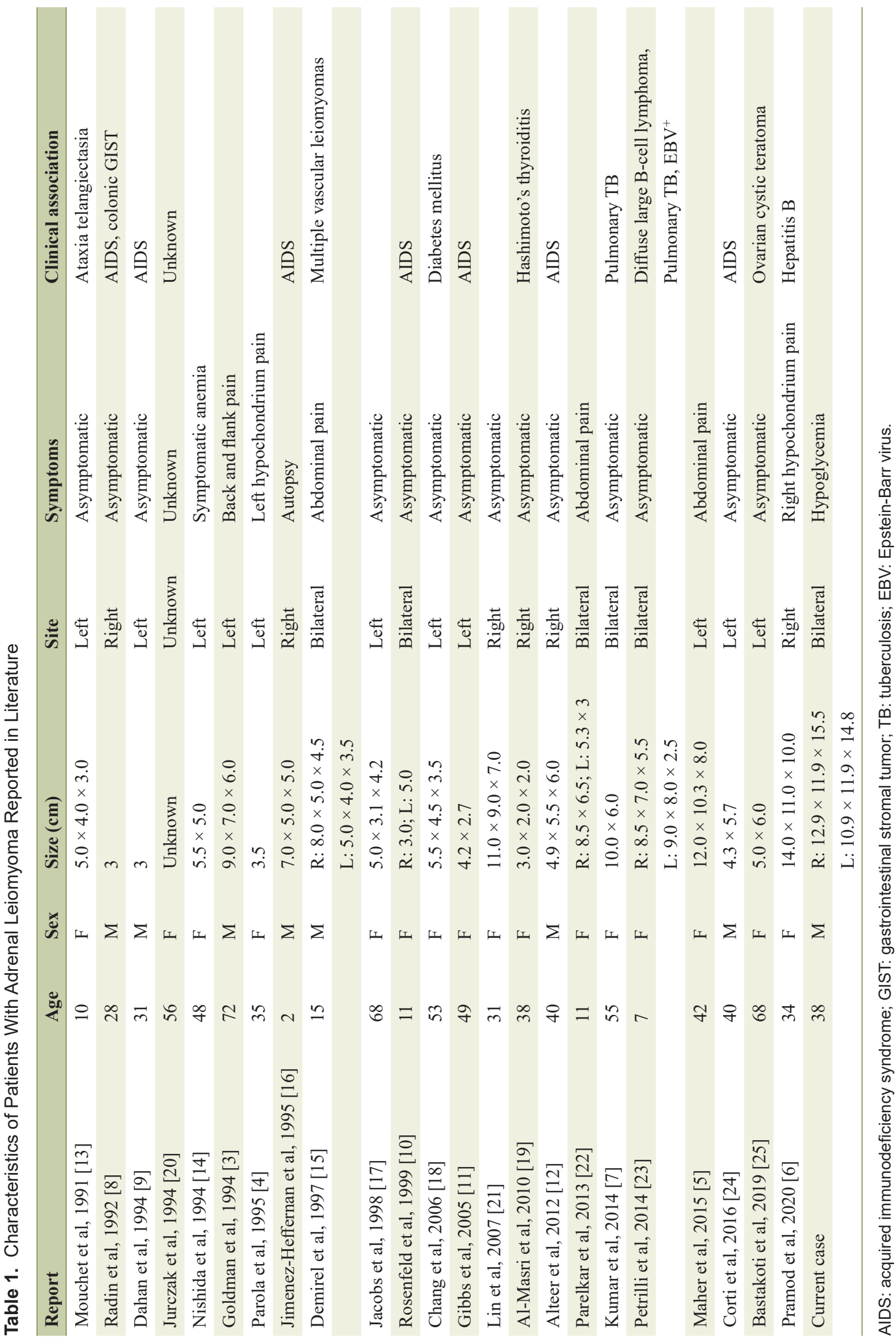
Data acquisition and manuscript preparation: Amy Cheng-Mei Khor.

\section{Data Availability}

Any inquiries regarding supporting data availability of this study should be directed to the corresponding author.

\section{References}

1. Oliveira Caiafa R, Salvador Izquierdo R, Bunesch Villalba L, Sebastia Cerqueda MC, Nicolau Molina C. [Diagnosis and management of adrenal incidentaloma]. Radiologia. 2011;53(6):516-530.

2. Young WF, Jr. Clinical practice. The incidentally discovered adrenal mass. N Engl J Med. 2007;356(6):601-610.

3. Goldman RL, Brodey PA. Symptomatic leiomyoma of the adrenal. Clin Imaging. 1994;18(4):277-278.

4. Parola P, Petit N, Azzedine A, Dhiver C, Gastaut JA. Symptomatic leiomyoma of the adrenal gland in a woman with AIDS. AIDS. 1996;10(3):340-341.

5. Meher D, Dutta D, Giri R, Kar M. Adrenal leiomyoma mimicking adrenal malignancy: diagnostic challenges and review of literature. Journal of Endocrinology and Metabolism. 2015;5(5):304-308.

6. Pramod SV, Siregar S, Safriadi F, Hernowo BS, Firdaus GI. The largest adrenal leiomyoma: A case report and literature review. Urol Case Rep. 2020;29:101106.

7. Kumar S, Nanjappa B, Agrawal P, Pushkarna A. Large bilateral adrenal leiomyomas presenting as calcified adrenal masses: a rare case report. Korean J Urol. 2014;55(5):363-366.

8. Radin DR, Kiyabu M. Multiple smooth-muscle tumors of the colon and adrenal gland in an adult with AIDS. AJR Am J Roentgenol. 1992;159(3):545-546.

9. Dahan H, Beges C, Weiss L, Abitbol M, Ledreff O, Teman G, Belattar K, et al. Leiomyoma of the adrenal gland in a patient with AIDS. Abdom Imaging. 1994;19(3):259261.

10. Rosenfeld DL, Girgis WS, Underberg-Davis SJ. Bilateral smooth-muscle tumors of the adrenals in a child with AIDS. Pediatr Radiol. 1999;29(5):376-378.

11. Gibbs KE, White A, Kaleya R. Laparoscopic management of an adrenal leiomyoma in an AIDS patient. A case report and review of the literature. JSLS. 2005;9(3):345348.

12. Alteer M, Ascott-Evans BH, Conradie M. Leiomyoma: a rare cause of adrenal incidentaloma. JEMDSA. 2012;18.

13. Mouchet F, Ninane J, Gosseye S, Verellen C, Bonnier C, Evrard P, Vermylen C, et al. Leiomyoma of the suprarenal gland in a child with ataxia-telangiectasia. Pediatr Hematol Oncol. 1991;8(3):235-241.

14. Nishida S, Tanimura A, Takasaki S, Nagaoka S, Fukueda M, Ikeda S, Matsuo K, et al. Surgically resected adrenal leiomyoma: report of a case. Surg Today. 1995;25(5):455457.

15. Demirel S, Erk O, Akkaya V, Tunaci A, Tanakol R, Terzioglu T, Demiryont M, et al. Multiple vascular leiomyomas involving bilateral adrenal glands, spleen, and epicardium, associated with bilateral testicular microlithiasis and empty sella turcica. J Pediatr Surg. 1997;32(9):13651367.

16. Jimenez-Heffernan JA, Hardisson D, Palacios J, GarciaViera M, Gamallo C, Nistal M. Adrenal gland leiomyoma in a child with acquired immunodeficiency syndrome. Pediatr Pathol Lab Med. 1995;15(6):923-929.

17. Jacobs IA, Kagan SA. Adrenal leiomyoma: a case report and review of the literature. J Surg Oncol. 1998;69(2):111112.

18. Chang TH, Lee YC, Liu CC, Huang CH, Wu WJ. Adrenal leiomyoma treated by hand-assisted laparoscopic adrenalectomy: a case report. Kaohsiung J Med Sci. 2006;22(11):575-579.

19. Al-Masri AA, Aladily TN, Younes NA. Unusual association between adrenal leiomyoma and autoimmune disease. Saudi Med J. 2010;31(2):199-201.

20. Jurczak F, Hamy A, Paineau J, Courant O, Visset J. [An unusual "incidentaloma": adrenal leiomyoma]. J Chir (Paris). 1994;131(8-9):391.

21. Lin J, Wasco MJ, Korobkin M, Doherty G, Giordano TJ. Leiomyoma of the adrenal gland presenting as a non-functioning adrenal incidentaloma: case report and review of the literature. Endocr Pathol. 2007;18(4):239243.

22. Parelkar SV, Sampat NP, Sanghvi BV, Joshi PB, Sahoo SK, Patel JL, Oak SN. Case report of bilateral adrenal leiomyoma with review of literature. Pediatr Surg Int. 2013;29(6):655-658.

23. Petrilli G, Lorenzi L, Paracchini R, Ubiali A, Schumacher RF, Cabassa P, Facchetti F. Epstein-Barr virus-associated adrenal smooth muscle tumors and disseminated diffuse large B-cell lymphoma in a child with common variable immunodeficiency: a case report and review of the literature. Int J Surg Pathol. 2014;22(8):712-721.

24. Marcelo Corti LDC, Lisandro Veliz, Ana Campitelli, Gabriela Acosta Haab. Adrenal leiomyoma: a rare tumor presented as an incidentaloma in a patient with AIDS. Mathews Journal of HIV/AIDS. 2016;1(2):6.

25. Bastakoti S, Nirmal L, Shrestha S, Dhunagana I. Adrenal leiomyoma: a rare tumour presented as an incidentaloma in a woman with ovarian mature cystic teratoma. Nepalese Journal of Cancer. 2019. 